Inflammatory bowel disease

\section{Chemokines in inflammatory bowel disease}

\section{S Danese, A Gasbarrini}

\section{Guilty of fatal attraction}

$C^{2}$ hemokines (chemotactic cytokines) are small (7-10 kDa) heparin binding proteins that govern the migration of circulating leucocytes to the sites of inflammation. ${ }^{1}$ Chemokines, currently numbering more than 50 , are classified into four supergene families based on cysteine residues: $\mathrm{CXC}, \mathrm{CC}, \mathrm{C}$, and $\mathrm{CX} 3 \mathrm{C}$ chemokines (table 1). ${ }^{2}$ Chemokines are distinguished from other cytokines by acting on the $G$ protein coupled serpentine receptors. ${ }^{2}$

Chemokines are classified into constitutively secreted and inducible. ${ }^{3}$ Those that are constitutively secreted are homeostatic chemokines directing basal leucocyte trafficking and the organisation of the lymphoid tissue. Inducible chemokines are inflammatory molecules responsible for mediating the recruitment of leucocyte effector populations to the sites of immune reaction and tissue injury. ${ }^{3}$

\begin{abstract}
"Aberrant leucocyte chemoattraction occurs in chronic inflammatory diseases and is characterised by an excessive recruitment of inflammatory cells into the injured tissue ${ }^{\prime \prime}$
\end{abstract}

The biological effects of chemokines are achieved by their interaction with specific receptors on the surface of the target cells. There are a few receptors that bind a single ligand, whereas several chemokines can bind to more than one receptor (table 1).

Aberrant leucocyte chemoattraction occurs in chronic inflammatory diseases and is characterised by an excessive recruitment of inflammatory cells into the injured tissue. In such processes, chemokines tightly control the multistep paradigm of leucocyte adhesion to and migration across the endothelium (fig 1). ${ }^{4}$ Ligation of chemokines to their receptors increases the affinity/avidity of leucocyte integrins for cell adhesion molecules, resulting in the switch from leucocyte rolling to firm arrest on the endothelial surface. ${ }^{4}$ Chemokines that regulate leucocyte firm adhesion are mainly produced by endothelial cells, interstitial cells, or rolling platelets.
Subsequently, the adhering leucocytes move across the endothelial barrier following a chemokine gradient produced by interstitial cells, which act as a satellite system providing crucial driving directions out from the vascular bed. ${ }^{14}$

Aberrant leucocyte chemoattraction probably occurs in all forms of tissue inflammation, including inflammation of the gut mucosa, because it is seen in Crohn's disease (CD) and ulcerative colitis (UC), the two major forms of inflammatory bowel disease (IBD). ${ }^{5}$ Although their aetiology is still unknown, in the past few years there have been great advances in the knowledge of the mediators that sustain chronic inflammation. In particular, it is now well established that chemokines play a central role in the pathogenesis of both forms of IBD, and are able to trigger multiple inflammatory actions including leucocyte activation and chemoattraction, granule exocytosis, production of metalloproteinases for matrix degradation, and upregulation of the oxidative burst. ${ }^{6}$

Several chemokines have been investigated in both $\mathrm{CD}$ and UC, and their expression is consistently increased during the active phases of the disease. ${ }^{67}$ In particular, interleukin 8 and its receptor are upregulated, as are monocyte chemotactic proteins 1 and 3, epithelial neutrophil activating protein 78 , macrophage inflammatory proteins $1 \alpha$ and $1 \beta$, interferon inducible protein 10 , stromal cell derived factor 1 , and fractalkine. $^{8-13}$ Of particular interest is the demonstration that RANTES (regulated on activation normal $\mathrm{T}$ cell expressed and excreted) expression is not only increased in human IBD, but has also been shown to play a crucial role in the transition from acute to chronic disease in experimental models of colitis, and to trigger leucocyte adhesion to the inflamed intestinal microvasculature. ${ }^{14-16}$ Moreover, some chemokines may be crucially relevant for regional specialisation of intestinal immunity. A clear example has been provided by the demonstration that thymus expressed chemokine is expressed exclusively in the small bowel but not in the colon. ${ }^{17}$ Furthermore, only lamina propria mononuclear cells resident in the small intestine express its receptor CCR9, thus providing direct evidence of a small intestinal "address code" for memory T cell homing. ${ }^{18}$

Among the many chemokines studied in IBD, almost no information exists regarding the expression of Epstein-Barr virus induced molecule-1 ligand chemokine (ELC/CCL19) and secondary lymphoid organ chemokine (SLC/CCL21), both belonging to the CC chemokine family. In this issue of the Journal of Clinical Pathology, Kawashima et al investigate the expression of both molecules and their unique receptor CCR7 in CD and UC. ${ }^{19}$ The authors find that CD
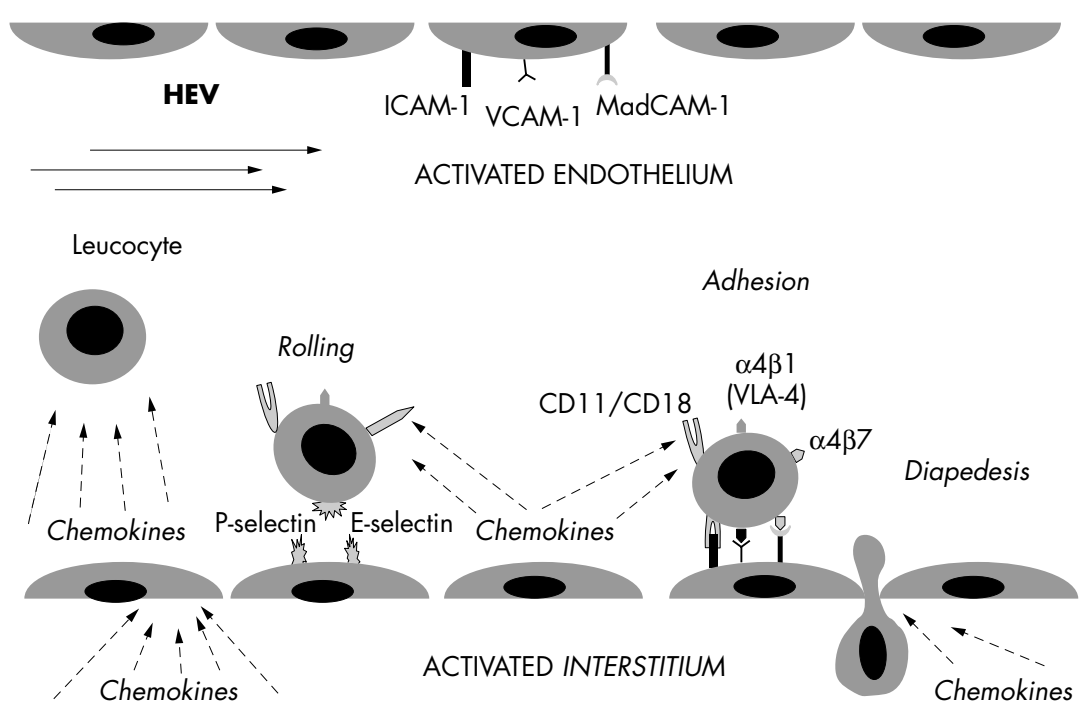

Figure 1 Chemokines in the multistep process of leucocyte adhesion. ICAM-1, intercellular adhesion molecule 1; MadCAM-1, mucosal addressin cell adhesion molecule 1; VLA-4, very late antigen 4 ; VCAM-1, vascular cell adhesion molecule 1. 
Table 1 C, CC, CXC, and CX3C chemokine/receptor families

\begin{tabular}{|c|c|c|}
\hline Systemic name & Classic name & Receptor \\
\hline \multicolumn{3}{|c|}{ C chemokine family } \\
\hline XCL1 & Lymphotactin & XCR 1 \\
\hline XCL2 & SCM $1-\alpha$ & XCR 1 \\
\hline \multicolumn{3}{|c|}{ CC chemokine family } \\
\hline CCLI & $1-309$ & CCR8 \\
\hline CCL2 & MCP-1 & CCR2 \\
\hline $\mathrm{CCL} 3$ & MIP-1 $\alpha$ & CCR1, CCR5 \\
\hline CCL4 & MIP-1 $\beta$ & CCR5 \\
\hline CCL5 & RANTES & CCR1, CCR3, CCR5 \\
\hline CCL6 & Unknown & Unknown \\
\hline CCL6 & Unknown & Unknown \\
\hline CCL7 & MCP-3 & CCR1, CCR2, CCR3 \\
\hline CCL8 & MCP-2 & CCR3 \\
\hline CCL9 & Unknown & Unknown \\
\hline CCL10 & Unknown & Unknown \\
\hline $\mathrm{CCL} 11$ & Eotaxin & CCR3 \\
\hline $\mathrm{CCL} 12$ & Unknown & CCR2 \\
\hline CCL13 & MCP-4 & CCR2, CCR3 \\
\hline CCL14 & HCC-1 & CCR1 \\
\hline CCL15 & HCC-2 & CCR1, CCR3 \\
\hline CCL16 & HCC- 4 & CCRI \\
\hline CCL17 & TARC & CCR4 \\
\hline $\mathrm{CCL} 18$ & DC-CK1 & Unknown \\
\hline CCL19 & ELC & CCR7 \\
\hline $\mathrm{CCL} 20$ & MIP- $3 \alpha$ & CCR6 \\
\hline $\mathrm{CCL} 21$ & SLC & CCR7 \\
\hline CCL22 & $M D C$ & CCR4 \\
\hline $\mathrm{CCL} 23$ & MPIF-1 & CCRI \\
\hline CCL24 & MPIF-2 & CCR3 \\
\hline CCL25 & TECK & CCR9 \\
\hline $\mathrm{CCL} 26$ & Eotaxin-3 & CCR3 \\
\hline CCL27 & CTACK & CCR10 \\
\hline CCL28 & MEC & CCRIO \\
\hline \multicolumn{3}{|c|}{ CXC chemokine family } \\
\hline CXCL1 & $\mathrm{GRO} \alpha$ & CXCR2 \\
\hline $\mathrm{CXCL2}$ & GRO $\beta$ & CXCR2 \\
\hline $\mathrm{CXCL3}$ & GRO $\gamma$ & CXCR2 \\
\hline CXCL4 & PF4 & Unknown \\
\hline CXCL5 & ENA-78 & CXCR2 \\
\hline CXCL6 & GCP-2 & CXCR1, CXCR2 \\
\hline CXCL7 & NAP-2 & CXCR2 \\
\hline CXCL8 & IL-8 & CXCR1, CXCR2 \\
\hline CXCL9 & MIG & CXCR3 \\
\hline CXCL10 & IP-10 & CXCR3 \\
\hline CXCL11 & I-TAC & CXCR3 \\
\hline CXCL12 & SDF- $1 \alpha$, SDF- $1 \beta$ & CXCR4 \\
\hline CXCL13 & BCA-1 & CXCR5 \\
\hline CXCL14 & BRAK & Unknown \\
\hline CXCL15 & Unknown & Unknown \\
\hline CXCL16 & Unknown & CXCR6 \\
\hline \multicolumn{3}{|c|}{ CX3C chemokine family } \\
\hline $\mathrm{CX} 3 \mathrm{CL} 1$ & Fractalkine & CX3CRI \\
\hline
\end{tabular}

BCA-1, B cell attracting chemokine 1; BRAK, breast and kidney cell chemokine; CTACK, cutaneous T cell attracting chemokine; DC-CK1, dendritic cell derived chemokine 1; ELC, EBII ligand chemokine; ENA78, epithelial neutrophil activating protein 78; GCP-2, granulocyte chemotactic protein 2; GRO, growth regulated oncogene; HCC, hepatocellular carcinoma; IL-8, interleukin 8; IP-10, interferon inducible protein 10; I-TAC, interferon inducible T cell chemoattractant; MCP, monocyte chemotactic protein; MDC, macrophage derived chemokine; MEK, mammary enriched chemokine; MIG, monokine induced by interferon $\gamma$; MIP, macrophage inflammatory protein; NAP-2, neutrophil activating protein 2; PF4, platelet factor 4; RANTES, regulated on activation normal T cell expressed and excreted; $\mathrm{SCM1} \alpha$, single C motif $1 \alpha$; SDF, stromal cell derived factor; SLC, secondary lymphoid tissue chemokine; TARK, thymus and activation regulated chemokine; TECK, thymus expressed chemokine.

mesenteric lymph nodes show increased expression of both SLC and ELC by immunohistochemistry. Furthermore, the cells displaying intense immunoreactivity were identified as high endothelial venules, dendritic cells, and lymphatic vessels, because of their colocalisation with the specific markers HECA452, CD83, and VEGFR3, respectively. In addition, Kawashima et al found a significant increase of the CCR7 receptor in CD but not in UC or healthy subjects, consistent with their observation of augmented CC ligand expression in $\mathrm{CD} .{ }^{19}$ Although the function of ELC and SLC is not known, the authors show immunoreactivity for the two chemokines predominantly in CD T cell lymph node areas, thus suggesting a role for $\mathrm{T}$ helper type 1 polarisation in the lymph node through the interactions between ELC and SLC positive high endothelial venule or dendritic cells and positive CCR7 T cells.
"In Crohn's disease both SLC and ELC and their CCR7 receptor are significantly overexpressed, leading to the hypothesis of a pathological role of these mediators in intestinal inflammation"

SLC and ELC are classified as constitutive chemokines. ${ }^{20}$ In particular, these two molecules are crucially relevant for the physiological development of lymph nodes and Peyer's patches. ${ }^{20}{ }^{21}$ Very recently, in addition to this classic task, a growing body of evidence has revealed that both SLC and ELC are significantly upregulated in chronic inflammatory conditions and may play a role in the pathogenesis of multiple diseases. ${ }^{20}$ In particular, SLC is responsible for leucocyte chemoattraction during renal inflammation, and the administration of a specific blocking antibody directed against SLC improved the survival of mesangial cells, suggesting a crucial effect of SLC in modulating kidney inflammatory processes. ${ }^{22}$ Similarly, SLC expression was found to be significantly increased in chronic liver disease and was selectively chemoattractive for CCR7 positive T cells, thus promoting the inflammatory response and fibrosis during chronic hepatitis. ${ }^{23}$ In addition, both ELC and SLC are upregulated in the central nervous system and play a crucial role in the attraction of encephalitogenic $\mathrm{T}$ cells during experimental autoimmune encephalomyelitis and in various inflammatory diseases of the central nervous system. ${ }^{24}$

Consistent with these observations, in CD both SLC and ELC and their CCR7 receptor are significantly overexpressed, leading to the hypothesis of a pathological role of these mediators in intestinal inflammation. Because many chemokines and their receptors have been successfully targeted for therapeutic intervention in several chronic inflammatory diseases, it would be useful to evaluate the clinical impact of SLC and ELC blockade in CD. ${ }^{25}$ Knowledge of the functional role of SLC and ELC and its potential relevance for IBD treatment would help us to understand whether their overexpression is just an epiphenomenon, or whether they play a key pathogenic role in gut inflammation, because they are guilty of the chemoattraction of pathogenic leucocytes into the gut.

\section{ACKNOWLEDGEMENT}

Supported by Ricerce in Medicine. The authors thank Dr Terzini for technical help.

J Clin Pathol 2005;58:1025-1027.

doi: 10.1136/jcp.2005.030916 


\section{Authors' affiliations}

S Danese, A Gasbarrini, Department of Internal Medicine, Gemelli Hospital, Catholic University, Rome 1-00168, Italy

Correspondence to: $\operatorname{Dr}$ S Danese, Department of Internal Medicine, Catholic University School of Medicine, Rome I-00168, Italy; sdanese@ hotmail.com

\section{REFERENCES}

1 Baggiolini M, Loetscher P. Chemokines in inflammation and immunity. Immunol Today 2000;21:418-20.

2 Bacon K, Baggiolini M, Broxmeyer $\mathrm{H}$, et al. Chemokine/chemokine receptor nomenclature. J Interferon Cytokine Res 2002;22:1067-8.

3 Laing KJ, Secombes CJ. Chemokines. Dev Comp Immunol 2004;28:443-60.

4 Baggiolini M. Chemokines and leukocyte traffic. Nature 1998:392:565-8.

5 Fiocchi C. Inflammatory bowel disease: etiology and pathogenesis. Gastroenterology 1998; 115:182-205.

6 MacDermott RP, Sanderson IR, Reinecker HC. The central role of chemokines (chemotactic cytokines) in the immunopathogenesis of ulcerative colitis and Crohn' disease. Inflamm Bowel Dis 1998;4:54-67.

7 Papadakis KA, Targan SR. The role of chemokines and chemokine receptors in mucosal inflammation. Inflamm Bowel Dis 2000;6:303-13.

8 Keshavarzian A, Fusunyan RD, Jacyno $M$, et al. Increased interleukin-8 (IL-8) in rectal dialysate from patients with ulcerative colitis: evidence for a biological role for IL-8 in inflammation of the colon. Am J Gastroenterol 1999;94:704-12.

9 Reinecker HC, Loh EY, Ringler DJ, et al.

Monocyte-chemoattractant protein 1 gene expression in intestinal epithelial cells and inflammatory bowel disease mucosa. Gastroenterology 1995; 108:40-50.

10 Z'Graggen K, Walz A, Mazzucchelli L, et al. The C-X-C chemokine ENA-78 is preferentially expressed in intestinal epithelium in inflammatory bowel disease. Gastroenterology 1997:113:808-16.

11 Uguccioni M, Gionchetti P, Robbiani DF, et al. Increased expression of IP-10, IL-8, MCP-1, and MCP-3 in ulcerative colitis. Am J Pathol 1999:155:331-6.

12 Katsuta T, Lim C, Shimoda K, et al. Interleukin-8 and SDF1-alpha mRNA expression in colonic biopsies from patients with inflammatory bowel disease. Am J Gastroenterol 2000;95:3157-64.

13 Muehlhoefer A, Saubermann $\sqcup$, Gu X, et al. Fractalkine is an epithelial and endothelial cellderived chemoattractant for intraepithelial lymphocytes in the small intestinal mucosa. J Immunol 2000;164:3368-76.

14 Ajuebor MN, Hogaboam CM, Kunkel SL, et al. The chemokine RANTES is a crucial mediator of the progression from acute to chronic colitis in the rat. J Immunol 2001;166:552-8.

15 Oki M, Ohtani H, Kinouchi Y, et al. Accumulation of CCR5+ T cells around RANTES+ granulomas in Crohn' disease: a pivotal site of Th1-shifted immune response? Lab Invest 2005;85:137-45.

16 Danese S, de La Motte C, Sturm A, et al. Platelets trigger a CD40-dependent inflammatory response in the microvasculature of inflammatory bowel disease patients. Gastroenterology 2003;124:1249-64.

17 Papadakis KA, Prehn J, Nelson V, et al. The role of thymus-expressed chemokine and its receptor
CCR9 on lymphocytes in the regional specialization of the mucosal immune system. $\mathrm{J}$ Immunol 2000; 165:5069-76.

18 Papadakis KA, Prehn J, Moreno ST, et al. CCR9positive lymphocytes and thymus-expressed chemokine distinguish small bowel from colonic Crohn' disease. Gastroenterology 2001;121:246-54

19 Kawashima D, Oshitani N, Jinnno Y, et al. Augmented expression of secondary lymphoid tissue chemokine (SLC) and EBII ligand chemokine (ELC) in Crohn's disease. J Clin Pathol 2005;58:1057-63

20 Serra HM, Baena-Cagnani CE, Eberhard Y. Is secondary lymphoid-organ chemokine (SLC) CCL21) much more than a constitutive chemokine? Allergy 2004;59:1219-23.

21 Muller G, Hopken UE, Lipp M. The impact of CCR7 and CXCR5 on lymphoid organ development and systemic immunity. Immunol Rev 2003; 195: 117-35.

22 Banas B, Wornle M, Berger T, et al. Roles of SLC/ CCL21 and CCR7 in human kidney for mesangial proliferation, migration, apoptosis, and tissue homeostasis. J Immunol 2002; 168:4301-7.

23 Bonacchi A, Petrai I, Defranco RM, et al. The chemokine CCL21 modulates lymphocyte recruitment and fibrosis in chronic hepatitis $\mathrm{C}$. Gastroenterology 2003;125:1060-76.

24 Alt C, Laschinger M, Engelhardt B. Functional expression of the lymphoid chemokines CCL19 (ELC) and CCL 21 (SLC) at the blood-brain barrier suggests their involvement in G-proteindependent lymphocyte recruitment into the central nervous system during experimental autoimmune encephalomyelitis. Eur J Immunol 2002:32:2133-44.

25 Johnson Z, Schwarz M, Power CA, et al. Multifaceted strategies to combat disease by interference with the chemokine system. Trends Immunol 2005;26:268-74.

\section{1 th European Forum on Quality Improvement in Health Care}

26-28 April 2006, Prague, Czech Republic

For further information please go to: www.quality.bmipg.com

Book early to benefit from a discounted delegate rate 